\author{
PETER KRIEGER
}

\title{
Reciclaje del pasado construido: notas sobre Agustín Hernández
}

Pre-texto

U

Na faceta considerable de la obra de Agustín Hernández, la adaptación de formas arquitectónico-esculturales mesoamericanas, se perfila con mayor claridad académica dentro de un marco conceptual que busca entender la importancia de las culturas antiguas no europeas para la génesis de la arquitectura moderna del siglo xx. Una primera contribución sólida para construir tal marco conceptual la ofreció un grupo de investigadores alemanes, estadounidenses y argentinos en el otoño de 2004, cuando reunieron a algunos historiadores de arquitectura dedicados a investigar los complejos procesos culturales que estimularon disidencias creativas de la arquitectura moderna ortodoxa. ${ }^{\text {I }}$

Es sabido que en la primera mitad del siglo pasado surgieron alternativas a la línea "clásica" de la arquitectura moderna, canonizada en la obra de Ludwig Mies van der Rohe, Walter Gropius y Le Corbusier. Basta citar el proyecto de Henri Sauvage para un conjunto de edificios en forma de terraza en la ribera del río Sena en París, de I928, donde emergen los contornos de una pirámide mesoamericana; el interés de Rudolf Schindler y Richard Neutra, arquitectos

I. Bernd Nicolai, Moderne und frühe Hochkulturen-Antiklassische Konzepte der Architektur der Moderne in interkultureller Perspektive (Modernity and Early Cultures-Reconsidering non-Western References for Modern Architecture in Cross-Cultural Perspective), coloquio, I5 y I6 de octubre, París, Centre Allemand d'Histoire de l'Art, reseñado por Gabriele D. Grawe en "Auf der Suche nach neuer Natürlichkeit", Frankfurter Allgemeine Zeitung, Io de noviembre de 2004. 
austriacos emigrados a California, EUA, por la arquitectura pueblo de Nuevo México, y la fase "neo-maya" de Frank Lloyd Wright.

Ciertos parámetros del give and take entre las culturas arquitectónicas europeas y americanas se cristalizan, y poseen también relevancia implícita para comprender el caso del arquitecto mexicano Agustín Hernández.

Desde la perspectiva europea, el interés arqueo-etnológico del siglo XIX en las civilizaciones de Medio Oriente y de América Latina inspiró a los arquitectos, artistas y también a los críticos de arte a principios del siglo xx a buscar características atemporales y globales de la arquitectura. Alentados por un debate sobre el arte "primitivo" durante la primera década del siglo xx, los arquitectos y sus críticos pretendieron revelar arcaicas fórmulas de patetismo, de la arquitectura monumental de todos los tiempos y culturas del mundo. Figuras clave en estos debates, por ejemplo en Alemania, fueron el crítico de arte Paul Westheim y el historiador Wilhelm Worringer, quienes, desde una perspectiva expresionista, encontraron en la abstracción de esas culturas arcaicas los modelos de una presunta unidad entre el hombre y la naturaleza.

Lo que hoy en día, en el contexto de la investigación estético-crítica, fácilmente se descalifica como figura neocolonial del pensamiento, extremada por un kitsch ontológico expresionista, de hecho, por mucho tiempo fue un generador que rompió la rutina ortodoxa y represora del movimiento moderno; es por ello que la inclusión de las culturas antiguas no europeas en el plan conceptual de la modernidad arquitectónica representó una interesante alternativa al clasicismo inherente de la arquitectura vanguardista, especialmente visible en la obra de Mies van der Rohe. ${ }^{2}$

Aquella fijación clásica predominante recibió su canonización cultural por parte de un historiador del arte: Rudolf Wittkower, quien disertó en 1949 sobre los fundamentos de la arquitectura en la edad del humanismo. ${ }^{3}$ Según una minuciosa investigación de Alina A. Payne, ${ }^{4}$ ese libro de Wittkower se prestó para reducir la arquitectura "clásica" de Palladio a parámetros abstractos, aptos para legitimar las cualidades de la entonces arquitectura moderno-con-

2. Peter Krieger, "Ludwig Mies van der Rohe y Karl Friedrich Schinkel. Interferencias, fecundaciones", Bitácora-Arquitectura, México, Universidad Nacional Autónoma de México-Facultad de Arquitectura, núm. I2, 2004, pp. 8-I3.

3. Rudolf Wittkower, Architectural Principles in the Age of Humanism, Londres, Warburg Institute, 1949.

4. Alina A. Payne, "Rudolf Wittkower and Architectural Principles in the Age of Modernism", Journal of the Society of Architectural Historians, núm. 53, septiembre de 1994, pp. 322-342. 
temporánea. Nociones como la claridad estructural o la fundación matemática de la composición arquitectónica, donde la forma surge como "verdad" esencial, fácilmente fueron traducidas a la racionalidad industrial de la arquitectura moderna, bauhausiana, corbusiana, etc. Sobre todo el historiador y también ideólogo central del movimiento moderno, Sigfried Giedion, recodificó la interpretación de Wittkower hacia una matrix de comprensión y legitimación del estilo arquitectónico moderno, y tal recodificación alcanzó, en los inicios de la segunda mitad del siglo $\mathrm{xx}$, un considerable éxito por medio de revistas de arquitectura como Casabella o Architectural Review y culminó en el ensayo de Colin Rowe sobre "las matemáticas de la villa ideal".5

Según esa construcción explicativa, el pasado clásico, que se remonta a más de dos milenios, aparece como presente eterno, y la entelequia de las formas grecorromanas, presente aún en la arquitectura de Mies van der Rohe, sirve como justificación cultural contemporánea. Ese mecanismo operacional se aplicó también al incluirse la tradición no occidental como fuente de inspiración arquitectónica.

Comparable a los esfuerzos europeos de rastrear, procesar y adaptar las propias raíces culturales a las necesidades contemporáneas por medio de la abstracción de características formales aparentemente eternas, también las influencias no europeas, en nuestro caso mesoamericanas, generan en la arquitectura contemporánea contradicciones implícitas, precisamente por su producción de identidades culturales normativas, unidimensionales e incluso irracionales. Cuando un arquitecto utiliza el fondo del lenguaje arquitectónico-histórico, casi en consecuencia inevitable, excluye la diversidad de los elementos auténticos de culturas arcaicas. Fácilmente se producen clichés visuales que sólo sirven como capital simbólico del arquitecto en sus mercados mentales y profesionales, pero no reflejan la intensidad y diversidad del original citado — una problemática que surgió mucho antes de los debates posmodernos de los años ochenta. La búsqueda de identidad a través del uso abstracto del fondo de estilos del pasado termina en la producción de lo que Marx —en otro contexto- llamó "máscaras de carácter", en productos socioculturales que prometen inconfundibilidad a cambio de trivialización.

Desde la perspectiva europea, la inclusión del fondo cultural oriental y latinoamericano, donde lo clásico se ve reemplazado por lo arcaico, implica

5. Colin Rowe, "The Mathematics of the Ideal Villa", Architectural Review, vol. IOI, I947, pp. IOI-IO4. 
una actitud neocolonial, en el sentido de que las culturas aparentemente inferiores o salvajes se refinan en la fusión con la cultura europea. Estudios sobre el impacto árabe o sudamericano en la obra de Le Corbusier, ${ }^{6}$ por ejemplo, han comprobado cómo ciertas culturas sirven como espejo de la propia situación y capacidad cultural. La construcción discursiva del otro en la configuración de la obra propia ofrece un potencial creativo considerable, no sólo en términos de creatividad arquitectónica, sino también en el nivel de ideologías culturales eurocentristas.

Desde la perspectiva latinoamericana, el reciclaje de estilos antiguos genera otras sinergias, especialmente con las definiciones decimonónicas de arquitectura nacional, vigentes - como lo demuestra el caso mexicano- hasta muy avanzado el siglo xx. En un país dominado —en lo arquitectónico- a lo largo de los últimos 500 años por el barroco sudeuropeo, el eclecticismo francés decimonónico y el modernismo estadounidense-internacional, no sorprende que la referencia a la arquitectura precolonial cumpla funciones normativas en la construcción de la identidad nacional. Al respecto, reporta el cronista Israel Katzman que desde el siglo Xvir surgieron interrogantes sobre el "papel de lo prehispánico", consolidado por excavaciones y estudios arqueológicos a partir de la última fase del siglo XIX.7 Sin rastrear con detalle la historia de la arquitectura mexicana a lo largo de la centuria pasada, es posible constatar que la referencia prehispánica casi se convirtió en una obligación para los arquitectos que querían vender sus fantasías creativas arquitectónicas como productos mexicanos.

En la genealogía virtual de arquitectos que exploraron y procesaron en su propia obra la herencia construida de Mesoamérica, destaca, como caso extremo, aunque al mismo tiempo significativo, Agustín Hernández.

\section{Pregunta}

¿Cómo transfiere este arquitecto motivos visuales y estructurales de la arquitectura mesoamericana a su producción personal? Hernández pretende establecer

6. Bruno Klein, "Le Corbusier y el Brasil-el Brasil y Le Corbusier”, en Helga von Kügelgen (ed.), Herencias indigenas, tradiciones europeas y la mirada europea (Indigenes Erbe, europäische Traditionen und der europäische Blick), Fráncfort del Meno, Vervuert, 2002, pp. 557-574; Zeynep Celik, "Learning from the Bidonville", Harvard Design Magazine, primavera/verano de 2003, pp. 69-74.

7. Israel Katzman, Arquitectura religiosa en México (I780-I830), México, Universidad Nacional Autónoma de México/Fondo de Cultura Económica, 2002, p. II. 
en su arquitectura "el diálogo que comunica a todas las épocas", incluso evocar "el urbanismo cósmico prehispánico". ${ }^{8}$ En su discurso para la Academia de Artes en 1992, el arquitecto perfila todo un concepto de transferencia e integración cultural en el proceso creativo del diseño arquitectónico a finales del siglo xx en México:

El cambio de espacios y culturas fue un choque violento que continúa viviendo en nuestro interior, conflicto en que sólo la abstracción y síntesis de nuestro legado histórico podrán conciliar la armonía espacial de la Arquitectura, para así poder continuar nuestra herencia creativa ancestral; siendo esta capacidad de vital importancia en el diseño arquitectónico, para poder encontrar en nuestra herencia cultural aquello que realmente podemos aprovechar, y para proyectarlo funcionalmente hacia el porvenir, logrando así una expresión de arte genuina con un espíritu de comunicación universal. ${ }^{9}$

Implícitamente, esa declaración anticipa un tópico que hasta la fecha, según diferentes corrientes políticas y académicas, se discute como "choque violento" de culturas. ${ }^{\text {IO }}$ La propuesta del arquitecto es la fusión de elementos culturales diferentes, e incluso excluyentes, en este caso para garantizar la continuación de la herencia mesoamericana en la arquitectura contemporánea. Con esto, Agustín Hernández rompe claramente con la prohibición de cualquier referencia histórica en la dogmática arquitectura moderna ortodoxa, difundida, por ejemplo, por Gropius, incluso, la cita demuestra que la estética mesoamericana es una contribución mexicana esencial a la "comunicación universal" sobre la arquitectura globalizada del siglo XxI, donde las referencias estilísticas ya no sólo se definen en los centros del primer mundo — como en los tiempos pico del international style—, sino también en las periferias culturales exóticas. ${ }^{\text {II }}$ Ese

8. Agustín Hernández, Praxis y pensamiento [discurso de ingreso a la Academia de Artes], México, Academia de Artes, I993, pp. 5-I2; Mario Pani, "Respuesta” [discurso pronunciado el 29 de octubre de 1992], en Agustín Hernández, op. cit., pp. I3-I6.

9. Ibidem, p. 8.

Io. Hernández expuso esa noción un año antes del famoso artículo "The Clash of Civilizations", escrito por Samuel Huntington en la revista Foreign Affairs (vol. 72, núm. 3, verano de 1993, pp. 22-28), posteriormente ampliado en el libro The Clash of Civilizations and the Remaking of World Order, Nueva York, Simon and Schuster, 1996.

II. Sobre ese mecanismo discursivo globalizado que define lo que es exótico y digno de entrar en los mercados mentales occidentales primermundistas véase mi artículo "Revolución y colonialismo en las artes visuales: el paradigma de la documenta", Universidad de México, núm. 6r7, noviembre de 2002, pp. 89-92. 
reclamo implícito de Hernández posiciona a México en el esquema cultural global como contribuyente al tesaurus de fórmulas visuales de carácter presuntamente eterno. ${ }^{\text {I2 }}$

También emana el mecanismo de fusión arquitectónica, justificado por su carácter de perdurabilidad y eternidad, por medio de la abstracción. ¿Pero cómo, en términos de diseño arquitectónico funciona la integración del legado histórico? ${ }^{13}$ Como medio virtual para explorar algunas opciones, Hernández aprovecha la libertad de las artes visuales y la poesía. En su libro Gravedad, geometría y simbolismo, que en su mayor parte consta de referencias europeas en la búsqueda de sentido de la arquitectura, Hernández presenta el poema "Tau", derivado del signo maya "T", codificado como el "IK" de Palenque. El poeta amateur lamenta: "Rota la continuidad / simbólica prehispánica. / Muda la protesta indígena: / ¡Una Tau labrada / detrás de una cruz Cristiana!” y explica un principio de la arquitectura mesoamericana digno de ser reanimado en los tiempos modernos: el "miedo al vacío / en los tableros" y el bajorrelieve que entrelaza: "/ un positivo de luz, / un negativo de sombra". I4

Una propuesta arquitectónica concreta para integrar un motivo abstracto de la cultura mesoamericana es el Centro de Meditación de Cuernavaca, Morelos (fig. I), diseñado en 1984, cuyo "nexo principal [es] con la cultura hindú", según la interpretación de Louise Noelle, ${ }^{\mathrm{IS}}$ aunque al mismo tiempo contiene una "reminiscencia prehispánica" que Beatriz de la Fuente ve en los contornos del edificio alusivo a una "cabeza de serpiente con sus fauces abiertas". Y más visible aún es la cita maya en la abertura de la pared en forma de "T"/"IK" invertida, que significa "germen de la vida eterna, el viento divino que silenciosamente se desliza por la noche". ${ }^{16}$ Además, la investigadora del arte prehispánico supuso

I2. Ese aspecto se expresa también en las escenografías del cine contemporáneo, que mezclan fragmentos arqueológico-visuales de diferentes culturas del mundo; por ejemplo, la película Lara Croft: Tomb Raider (200I, director Simon West). Un inicio prominente del uso de la arquitectura mesoamericana como fórmula visual en el cine globalizado fue una escena al final de la película 007Moonraker (1979, director Lewis Gilbert, diseñador Ken Adam), filmada en Tikal, Guatemala.

I3. Hernández, Discurso de ingreso..., op. cit., "sólo la abstracción y síntesis de nuestro legado histórico".

I4. Agustín Hernández, Gravedad, geometría y simbolismo, Beatriz de la Fuente (prólogo), México, Universidad Nacional Autónoma de México-Facultad de Arquitectura, 1989, pp. 9I-93.

I5. Louise Noelle, Agustín Hernández, Barcelona/México, GG (Catálogos de Arquitectura Mexicana), 1995, p. 48.

I6. Beatriz de la Fuente, “El ‘Centro de Meditación’ en Cuernavaca, Morelos, de Agustín Hernández”, Anales del Instituto de Investigaciones Estéticas, vol. XIV, núm. 55, 1986, p. I08. 


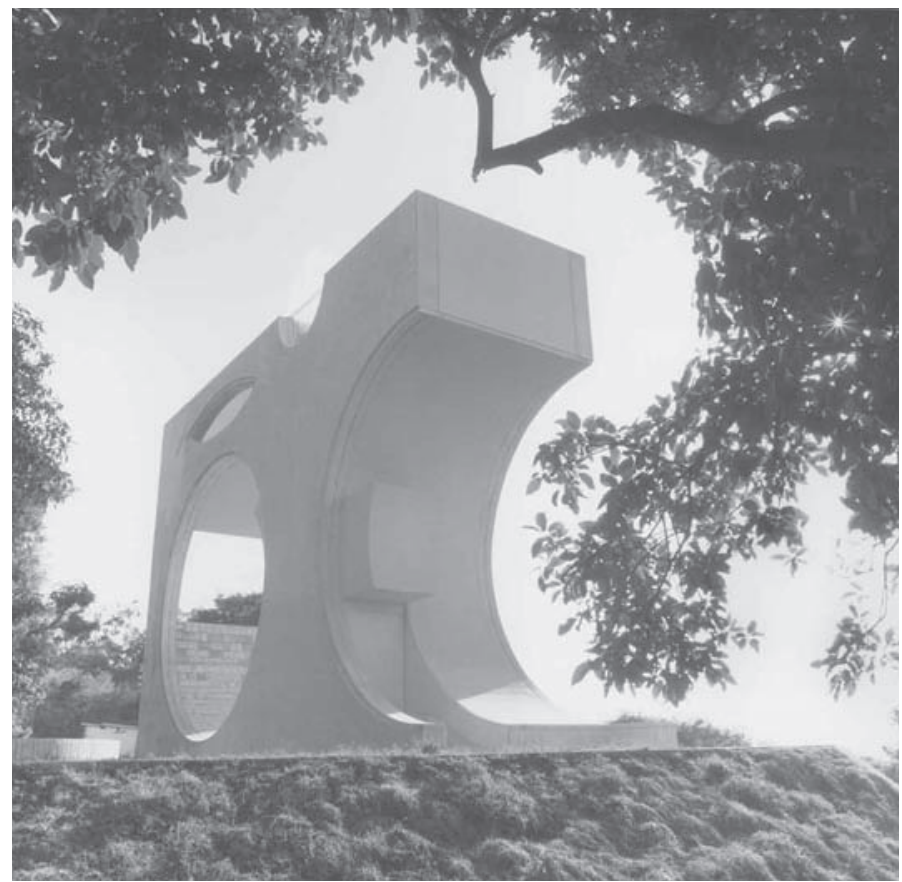

I. Agustín Hernández, Centro de Meditación, Cuernavaca, 1984. Archivo personal Louise Noelle.

que el orden geométrico del edificio, con sus formas circulares y semicirculares, "recuerda la perfecta unidad [...] de un templo maya" ${ }^{77}$ Todo ello, según De la Fuente, comprueba que Agustín Hernández "ha renovado el significado de monumentos ancestrales al incorporar, actualizándolas, partes de ellos". ${ }^{8}$

Mientras se interpreta una actualización y abstracción de un motivo mesoamericano en la arquitectura contemporánea mexicana —expresada por el arquitecto mismo en una reflexión poética libre- con base en el conocimiento preciso de la investigación estética que tiene registrado el aparato formal y simbólico de la arquitectura maya, hay otros acercamientos que confirman, de una u otra manera, que Agustín Hernández transformó fragmentos de la herencia prehispánica en su obra.

17. Ibidem, p. Io9.

I8. Ibidem, p. Io8. 


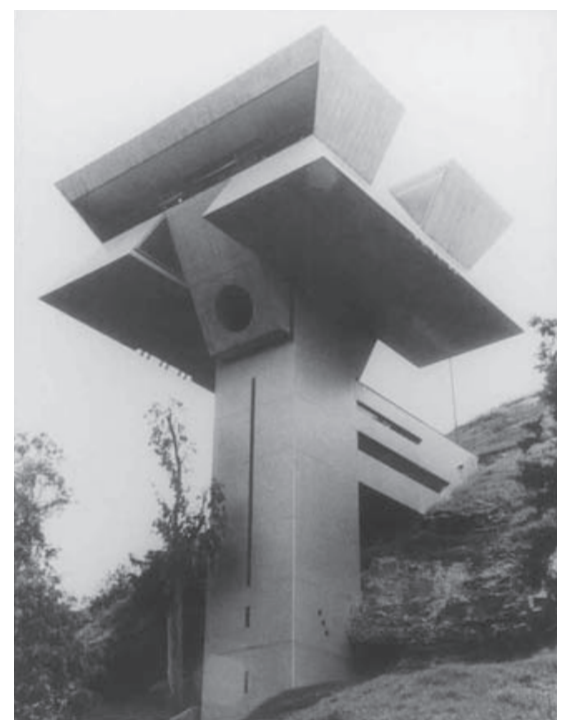

2. Agustín Hernández, taller del arquitecto, ciudad de México, 1972. Archivo personal Louise Noelle.

Desde la crítica e historia de la arquitectura tardía del siglo xx, Noelle certifica que el arquitecto busca "tanto en las técnicas modernas y en la geometría, como en las raíces prehispánicas, la respuesta para lograr una Arquitectura Mexicana Moderna". ${ }^{19}$ A nivel conceptual, la modernidad tecnológico-constructiva y la tradición cultural mesoamericana generan una sinergia, visible en el taller del arquitecto, diseñado en 1972 (figs. 2 y 3), donde una estela de concreto armado carga una pirámide invertida del Tajín, según Noelle una "agresividad de los cuerpos exteriores de reminiscencias prehispánicas" ${ }^{20}$ Además, la escalera de caracol interna alude quizás a la espiral del observatorio de Chichén Itzá o a la cerámica de la Huaxteca, aunque, como observó Beatriz de la Fuente, la espiral es más bien un signo universal de fertilidad, del inicio y del fin, cuyas dimensiones estéticas Hernández exploró en varios trabajos esculturales de cerámica.

El taller de Agustín Hernández, su máxima tarjeta de visita, incluye, entonces, motivos mesoamericanos, pero al mismo tiempo explora de manera lúdico-escultural una combinación completamente tardío-moderna, tal vez apta para la filmación de una película 007 James Bond. Es una combinación de

19. Louise Noelle, Agustín Hernández. Arquitectura y pensamiento, México, Universidad Nacional Autónoma de México-Instituto de Investigaciones Estéticas, 1982, p. 22.

20. Noelle, Agustín Hernández, op. cit., p. Io. 


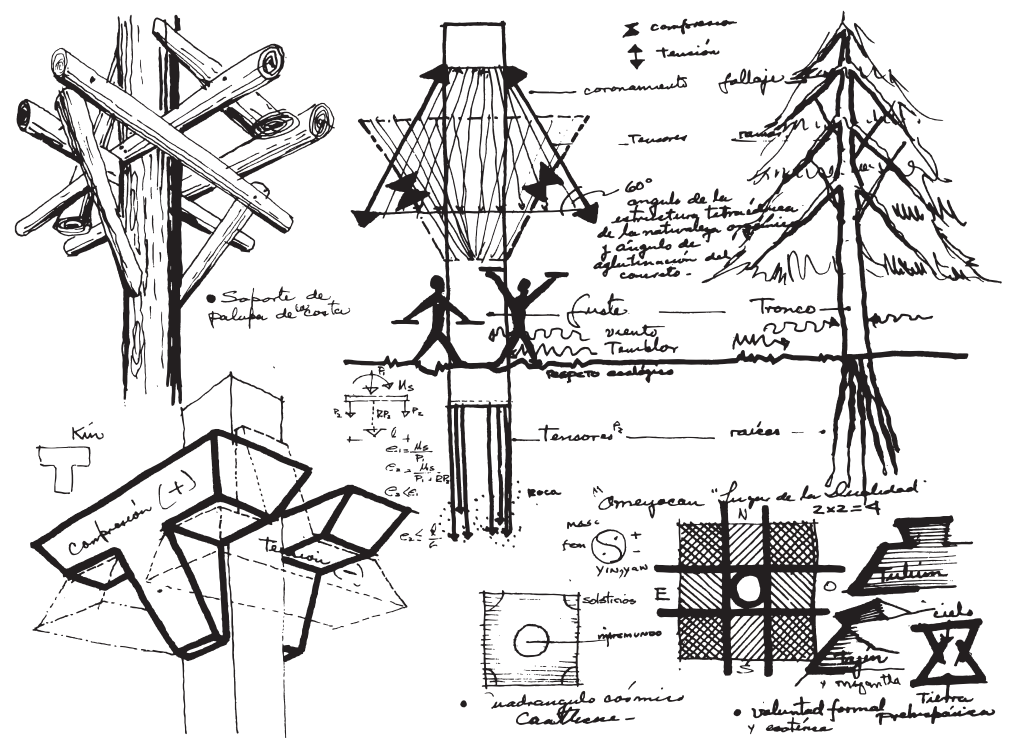

3. Agustín Hernández, dibujo del taller del arquitecto, 1972. Archivo personal Louise Noelle.

volúmenes construidos que disuelve el choque de las culturas — prehispánica y contemporánea - en una composición ad libitum del arquitecto. No se utiliza la referencia mesoamericana como camisa de fuerza.

Ese aspecto de la libertad creativa en las composiciones lo subraya, con licencia de asociación libre, y con cierta imprecisión terminológica, el artista Federico Silva en el prólogo de un libro sobre arquitectura y pensamiento de Hernández:

Tlatilco, Teotihuacán, Chichén Itzá para Agustín Hernández son remotas referencias pero que al proyectar sus volúmenes y claroscuros deben estar presentes como vibraciones sensibles de la piel o quizá de la memoria, pero no para copiar soluciones formales, sino para provocar un acto de esencial importancia, trascender el presente. ${ }^{2 \mathrm{I}}$

2I. Federico Silva, "Prólogo", en Noelle, Agustín Hernández. Arquitectura..., op. cit., p. 8. 


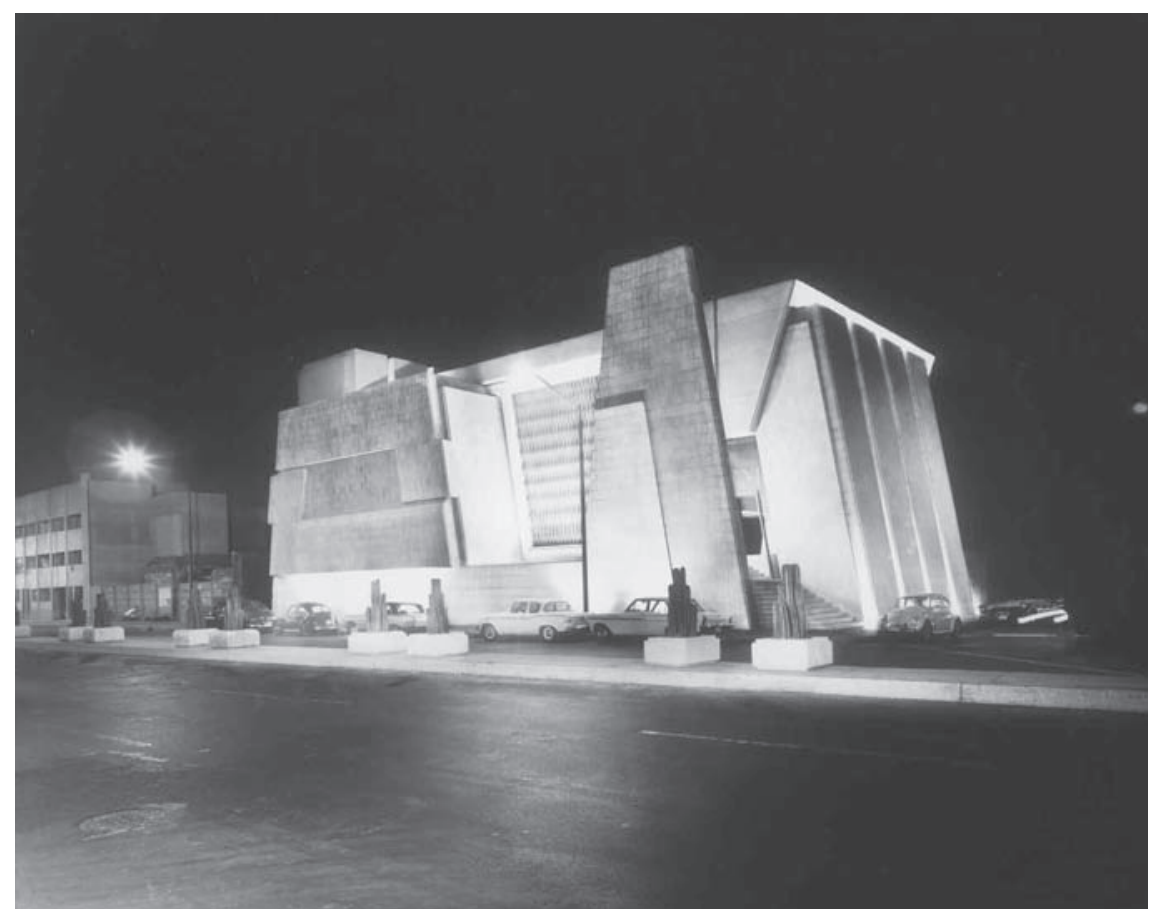

4. Agustín Hernández, Escuela del Ballet Folklórico de México, ciudad de México, 1965. Archivo personal Louise Noelle.

La cohesión de elementos sueltos, antiguos y modernos, se ilustra en el edificio de la Escuela del Ballet Folklórico de México (fig. 4), un diseño de 1965 clasificado por Noelle como una "escultura habitable", donde "el movimiento de inspiración prehispánica fue el condicionante del diseño". ${ }^{22}$ Más precisamente, según la evaluación de Beatriz de la Fuente, sólo detalles, como el cambio de las celosías con los muros lisos, que recuerda el estilo Ph'uc; las molduras parecidas a las encontradas en Monte Albán (fig. 5); las alfardas, como en un templo del Posclásico tardío, y tal vez los lineamientos y contrastes de luz, evocan el pasado de México antes de la aculturación española.

Frente al abismo de la cultura arquitectónica virreinal, las diferentes culturas prehispánicas surgen, en la retrospectiva del contemporáneo, como unidad; a la vez, en la obra de Hernández se enlazan tales mezclas como remotas referen- 
5. Beatriz de la Fuente, dibujo de las molduras de Monte Albán, 2004. Archivo personal Peter Krieger.

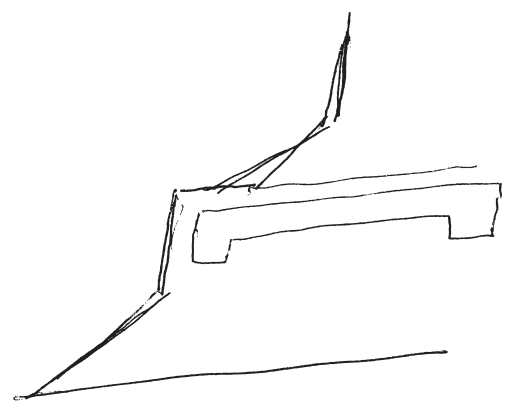

cias. Es una homogeneización a posteriori de las culturas mesoamericanas que surge en la conciencia del arquitecto y algunos de sus intérpretes. En el terreno periodístico, ese proceso de simplificación es aún más problemático. Una revista pretenciosa de bienes raíces, por ejemplo, publicó en la primavera de 2006 un retrato del arquitecto con este título: "La pasión por el nacionalismo: Agustín Hernández"; en la portada de dicha revista se colocó un título incluso más dramático: "Agustín Hernández. De esencia mexicana". ${ }^{23}$

La artificial construcción de identidad nacional mexicana, donde están disponibles los mitos y las historias igual que los motivos arquitectónicos, en el caso aquí tratado se centra en un tipo de kitsch biográfico, usual en muchos reportajes sobre arquitectos contemporáneos del mundo. Myriam Audiffred Lara relata en su artículo que Hernández jugó de niño en Tuxpan, Veracruz, con figurillas de tipo mesoamericano, de piedra y barro. Ve ese dato biográfico extrapolado como acto de iniciación en la cultura mesoamericana que, según la lógica reducida de esa construcción periodística, indujo al arquitecto a recorrer las zonas arqueológicas del país para efectuar estudios etnográficos y coleccionar impresiones estéticas. Culmina esa presentación con esta cita del arquitecto: "Yo siempre fui un amante de lo prehispánico." ${ }^{24}$

Sin cuestionar la autenticidad de esa cita o poner en duda que el joven Hernández se inició con las citadas figurillas, surge la necesidad, desde una perspectiva académica, de explorar de otra manera las formas de creatividad arquitectónica inspirada por el arte mesoamericano más allá de la fijación biográfica y su reducción periodística.

23. Myriam Audiffred Lara, "La pasión por el nacionalismo: Agustín Hernández", en Hábitat, arquitectura, diseño, bienes raices, 2006, pp. 28-31.

24. Ibidem, p. 29. 


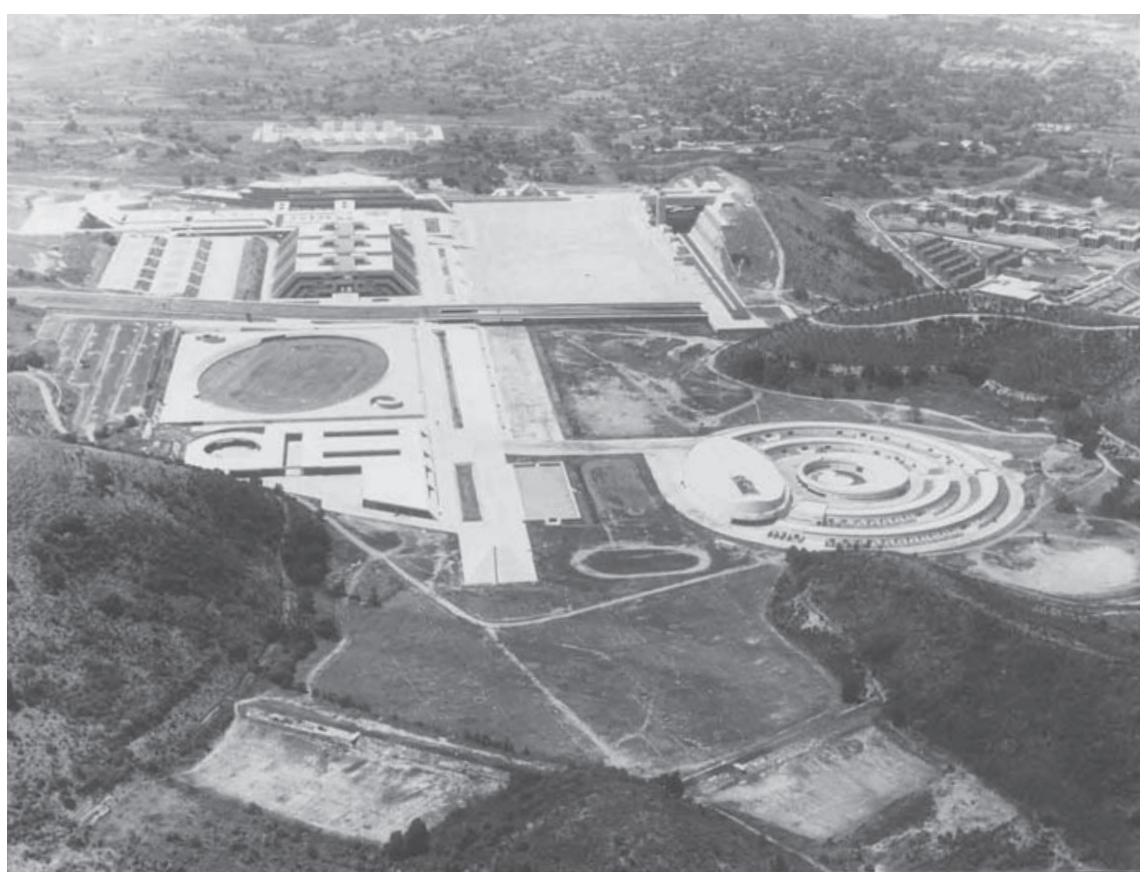

6. Agustín Hernández, Heroico Colegio Militar, ciudad de México, 1974. Archivo personal Louise Noelle.

\section{Preliminares}

La doctora De la Fuente, investigadora reconocida en el campo del arte mesoamericano, me ayudó en el proceso de "limpiar" de los estereotipos circulantes el estudio en curso sobre Agustín Hernández con algunas observaciones contundentes. ${ }^{25} \mathrm{El}$ sentido de este breve texto, que retoma su información respecto al tema, es configurar las primeras bases de una construcción biográfica crítica, con el enfoque, que esbocé en las primeras páginas, sobre el "pre-texto" del interés y de la investigación.

Más allá de los comentarios puntuales, De la Fuente, amiga cercana del arquitecto, me orientó en torno a algunos puntos centrales de ese caso de trans-

25. Durante el otoño de 2004 y principios de 2005 , la doctora me concedió una serie de entrevistas (no grabadas) relativas a la presencia de motivos mesoamericanos en la obra de Agustín Hernández. 


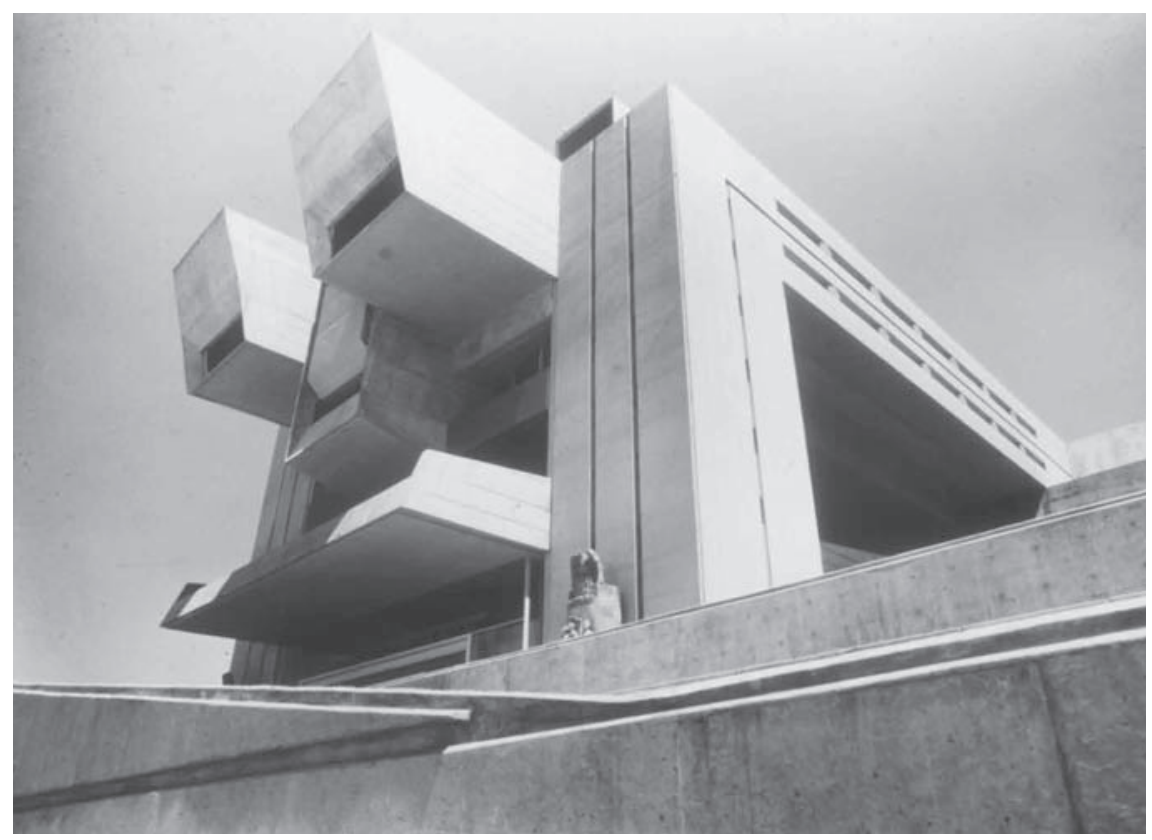

7. Agustín Hernández, Heroico Colegio Militar, ciudad de México, 1974. Archivo personal Louise Noelle.

ferencia cultural entre tiempos y espacios, épocas y regiones. Ella mencionó que Hernández no adquirió su conocimiento de la arquitectura mesoamericana por medio de estudios académicos, sino de una manera más directa, explorando los sitios arqueológicos con una mirada interesada, abierta, posteriormente transformada en innumerables series de dibujos. El arquitecto se deja guiar por la fascinación, "se apoya en lo que ve", ${ }^{26}$ y lo procesa en su mente creativa sin reglas definidas, sin sistema académico en el registro de los monumentos mesoamericanos. Es decir, las influencias obvias de la cultura antigua mexicana en la arquitectura contemporánea de Agustín Hernández se basan en introspecciones personales, no en estudios profundos de extensas bibliografías.

Destaca en este proceso creativo que el arquitecto desarrolla más interés en los volúmenes y menos en los espacios interiores de los edificios mesoamericanos, aspecto que emana con mayor claridad en sus esculturas, que adoptan las 


\section{6}

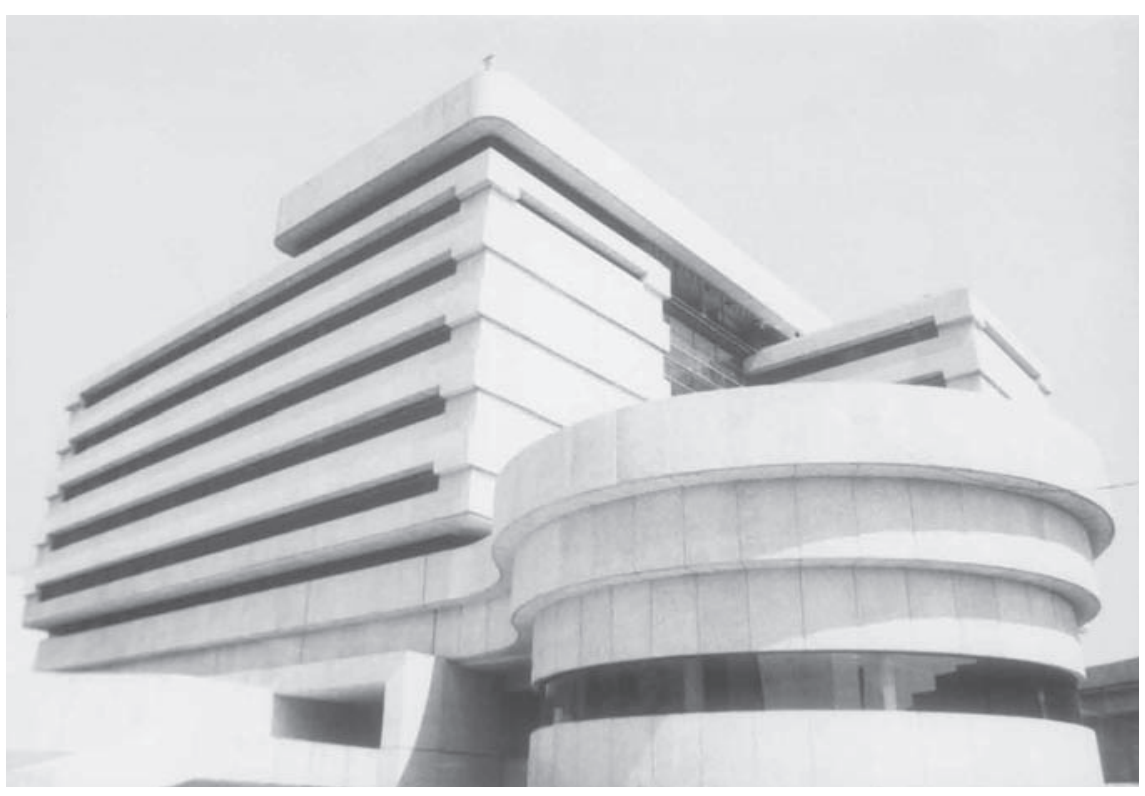

8. Agustín Hernández, Centro Hospitalario Villa Obregón (Instituto Mexicano del Seguro Social), Río Magdalena, ciudad de México, 1973. Archivo personal Louise Noelle.

formas básicas piramidales, cúbicas, como entidad estética de eternidad. Esto se demuestra claramente en el proyecto del Heroico Colegio Militar (figs. 6 y 7 ), de 1974, donde Hernández se inspiró en "centros ceremoniales prehispánicos", 27 en concreto en Teotihuacan por su índole urbano-espacial, en el Tajín por su espacio hundido y en Monte Albán por su asimetría. ${ }^{28}$

Detalles como los muros en talud, parecidos a Teotihuacan, o megaornamentos como la fachada del edificio de Gobierno del Colegio Militar, a la manera del mascarón del dios maya Chaac, ${ }^{29}$ confirman la hipótesis de Noelle de que la "tesis fundamental del proyecto fue la de conservar las raíces culturales de México", 30 aunque, como indica Beatriz de la Fuente, hay que marcar también las diferencias, los elementos que no caben en el esquema de la adaptación prehispánica.

27. Noelle, Agustín Hernández, op. cit., p. 34.

28. Todas esas referencias las tomé de las entrevistas ya citadas con Beatriz de la Fuente.

29. Noelle, Agustín Hernández. Arquitectura..., op. cit., p. Io6.

3o. Idem. 
Sin duda, el efecto panorámico del conjunto con sus formas piramidales evoca lo arcaico de un sitio arqueológico mesoamericano. Pero la triple división del edificio piramidal y su cortina reflejante de vidrio obviamente no existen en la arquitectura prehispánica. Tampoco existían en esas culturas la combinación de círculos que propone Hernández. ${ }^{31}$ Son ésas las libertades que se toma el arquitecto en la mezcolanza cerebral del proceso creativo, cuando un principio del pasado se fusiona con la estética y la construcción modernas. Hernández no pretendió componer un falso neohistórico ni tampoco un collage posmoderno (con elementos sueltos), sino una fusión conceptual con identidad estructural propia.

No obstante, hay diferentes escalas al respecto en la obra de Agustín Hernández. En su proceso de mezcla formal por medio de abstracciones geométricas, surgen soluciones contradictorias como el Centro Hospitalario Villa Obregón (Instituto Mexicano del Seguro Social), Río Magdalena ${ }^{32}$ (fig. 8), de I973, donde el arquitecto adoptó de Monte Albán el talud y el efecto de sombra que separa los cuerpos arquitectónicos, aunque inventó libremente la combinación de círculos y la formación de la textura.

Las conversaciones con la doctora De la Fuente revelaron las fuentes de inspiración mesoamericana del arquitecto Agustín Hernández, aunque también los límites. En nuestra disciplina, que de vez en cuando tiende a sobreinterpretar las formas artísticas, es una tarea de crítica necesaria.

Por último, es interesante mencionar la comparación de Hernández con otro arquitecto mexicano contemporáneo que ha ganado gran reputación: Pedro Ramírez Vázquez. Según Beatriz de la Fuente, Ramírez Vázquez sólo recoge elementos aislados de la arquitectura mesoamericana, los estiliza e integra a manera de collage en su concepto arquitectónico tardío-moderno, como lo demuestra la celosía del Museo Nacional de Antropología, que cita un detalle significativo de Uxmal. En comparación con esa actitud de un arquitecto que "toma voluntariamente elementos aislados", Agustín Hernández resulta "más atraído por soluciones espaciales" 33 y por ello sus interpretaciones del pasado parecen más coherentes.

Esas reflexiones son los primeros pasos de una investigación, una base para futuras indagaciones, en especial respecto a las funciones que cumple la arquitectura

3I. Entrevista con Beatriz de la Fuente.

32. Noelle, Agustín Hernández, op. cit., pp. 30-33; Noelle, "Hospital de Gineco-obstetricia núm. 8 y Clínica Hospital T-I”, en Agustín Hernández. Arquitectura, op. cit., pp. 96-I05.

33. Entrevista con Beatriz de la Fuente. 
contemporánea con referencias prehispánicas en el esquema cultural de México. Queda claro que el tema y problema es éste: de qué manera y con qué efectos las analogías formales con la herencia arquitectónica del pasado generan identidad nacional, un terreno de difícil interpretación, altamente complejo y sembrado de muchas trampas epistemológicas. Es tema de una futura publicación. \$

Fe de erratas de Anales 88

En la nota 5 del artículo de Emilie Carreón Blaine dice Antonio Rubial (comp.); debe decir Pablo Escalante Gonzalbo. 